\title{
PODE SER DIFÍCIL, MAS NÃO IMPOSSÍVEL...
}

\author{
Maria Ermineide de Paula Lima ${ }^{1}$
}

Resumo: O presente texto trata do memorial sobre a trajetória escolar de Maria Ermineide de Paula Lima, ex-integrante do Programa Conexões de Saberes. Tem como objetivo apresentar os passos percorridos desde o início da educação básica até a entrada à UFPA e quais os principais entraves de estudantes das comunidades populares adentrarem o ensino superior público. A memória foi usada como principal referência para construção do material. Em seus resultados, apresenta os esforços individual e coletivo para que de fato a educação seja uma questão de direito e não de privilégio de poucos.

$$
\begin{array}{r}
\text { Um dia você aprende que... } \\
\text { depois de algum tempo você aprende a diferença, } \\
\text { a sutil diferença, entre dar a mão e acorrentar uma alma. } \\
\text { E você aprende que amar não significa apoiar-se, } \\
\text { e que companhia nem sempre significa segurança. } \\
\text { E começa a aprender que beijos não são contratos } \\
\text { e presentes não são promessas. } \\
\text { E começa a aceitar suas derrotas com a cabeça erguida } \\
\text { e olhos adiante, com a graça de um adulto } \\
\text { e não com a tristeza de uma criança. } \\
\text { E aprende a construir todas as suas estradas no hoje, } \\
\text { porque o terreno do amanha é incerto demais para os planos, } \\
\text { e o futuro tem o costume de cair em meio ao vão. } \\
\text { Depois de um tempo você aprende que o sol queima } \\
\text { se ficar exposto por muito tempo... } \\
\text { E aprende que não importa o quanto você se importe, } \\
\text { algumas pessoas simplesmente não se importam... }
\end{array}
$$

A vida é um aprendizado constante, assim como nesses versos aprendi que a superação é a palavra que define as minhas conquistas, mesmo que isso para muito não signifique absolutamente nada. Mas para mim estudante oriunda das classes populares é vencer as dificuldades.

Penso que este memorial retrata exatamente as estradas que percorri até hoje, mostrando a importante trajetória de meus encontros, desencontros e todo aprendizado que eu pude tirar deles. Este exercício levou-me a refletir e analisar em que os fatos ocorridos influenciaram na formação do meu caráter e na construção de minha historia de vida.

No entanto, elaborar este memorial não foi tarefa fácil, pois escrever sobre de minha vida é na verdade fazer uma seleção dos fatos mais relevantes desta trajetória, “... tentei não apenas descrever minha experiência passada: tentei deixar que essa experiência falasse de si, tentei pensá-la..." (SOARES, p.15) e procurei pontuar o que fosse significativo em minha

\footnotetext{
${ }^{1}$ Especialização em Educação Ambiental pela Universidade Federal do Pará, e-mail: neideufpa@yahoo.com.br ${ }^{2}$ Versos deste poema são de "O Menestrel” de William Shakespeare
} 
trajetória para que a partir das experiências que vivenciei tenham significância a outras pessoas.

Vivências de mulher, mãe, esposa, comerciária e estudante de escola pública e cursinho popular. Processos individuais e coletivos que possibilitaram a superação de paradigmas e a construção de uma nova trajetória de vida estabelecida a partir das relações entre eu e o mundo. Passar no vestibular foi um momento inesquecível e único em minha vida. Quer experimentar? Embarque nesta historia e acredite em seus sonhos.

\section{A família: início da trajetória}

...aprende que há mais dos seus pais em você do que você supunha.

Nasci na cidade de Belém do Pará, sou a última filha de uma família de três irmãos e quatro irmãs, meu pai era vigia no Forno Crematório localizado no Bairro da Cremação onde moramos até os dias atuais, hoje no local é uma praça "Darcilio Jurandir", gostava muito de correr por lá, sempre que vou a esta praça fico lembrando, como fui uma criança feliz. Mamãe trabalhava de lavadeira e eles sempre enfrentaram a vida com determinação e coragem para dar o melhor a seus filhos.

Sempre gostei deste bairro mesmo sem o mínimo de estrutura para viver, na rua que eu moro não tinha e não tem saneamento básico, andamos em cima de pontes e quando chove o canal transborda e a rua fica alagada, depois de um tempo melhorou um pouco, não há mais ponte. Recordo que na cidade sempre chovia depois das três horas da tarde, atualmente devido às mudanças climáticas, este fenômeno não acontece com freqüência, mas na minha infância eu brincava na rua e eram freqüentes os banhos de chuva. Hoje este local é considerado área de risco, pois a criminalidade é constante, as nossas crianças não podem brincar mais na rua, pois acabam sendo vitima de balas perdidas... Vivemos sobre perigo constante.

Voltando para minha infância em casa meu pai era especial, engraçado e extrovertido de muitos amigos e gostava de contar estórias de terror para mim e meus irmãos, ficávamos com muito medo. Ele era demais!

Gostava de ler a bíblia para nós e esse foi o meu primeiro contato com a leitura, sentávamos ao lado dele no chão da sala sendo essa atividade fundamental para minha formação no que refere a construção de valores, respeito a Deus e ao próximo. Papai tinha uma leitura exemplar tanto ele quanto minha mãe, ambos tendo estudado apenas até a $4^{\mathrm{a}}$ série primaria, por conta de precisarem ajudar a família, mas ele jamais abandonou o hábito de ler. 
Além disso, o contato com a leitura, mesmo como ouvinte, aguçava a minha curiosidade sobre aquele mundo da escrita que eu não conhecia. Um trecho dizia "o senhor é meu pastor e nada me faltara". Mas faltava e muito, chegou um tempo de necessidades, em que a situação obrigou minha irmã Gorete e meu irmão Carlos em busca de alimentação para nós. Iam ao mercado de peixe de São Brás (Bairro de Belém) e juntavam muitas cabeças de peixe e traziam para que nós pudéssemos nos alimentar, precisávamos sobreviver e essa era a alternativa.

Contar esta fase de minha vida não é difícil, o mais difícil e saber que essa não é uma história do passado é muito atual, percebe-se que crianças ainda catam em lixo alimentação para ajudar a família e uma grande parte delas acaba saindo da escola. Na minha família meus irmãos não terminaram nem o ensino fundamental eles foram logo para o trabalho informal e minhas irmães foram para o trabalho doméstico.

Mesmo com essas dificuldades acabamos superando e não impediu que meus pais nos possibilitassem a criação de valores para a formação de nosso caráter, pois ensinavam que devemos conquistar com nosso esforço e jamais passar por cima das pessoas para alcançar os nossos objetivos. Neste ambiente de determinação e superação que eu fui criada e não me abalo diante das situações difíceis.

\section{E o que importa não é o que você tem na vida, mas que você é na vida.}

\section{O caminho na Escola Pública: o processo de ensino e aprendizagem.}

No ano de 1978 comecei a estudar, que emoção! Fiquei tão contente com o caderno e o lápis, eu ficava cheirando o tempo todo, pois era tudo novo e o uniforme então, que beleza! Blusa branca e saia de prega tudo a contento.

A Escola Antonio Carvalho Brasil era pequena havia: quatro salas, a merenda uma delícia (quem não comeu aquele macarrão com sardinha heim?). Tinha uns meninos que gostavam de me bater, mas minha irmã Socorro estudava na sala ao lado e no recreio resolvia estes conflitos (batendo também). Sem dvida ela era minha salvadora, lembro de como brincávamos de roda durante o recreio me sentia muito alegre.

Só que esta alegria acabava na sala de aula apesar de eu ser uma criança que gostava de falar, aprendi logo cedo na escola que uma criança educada era aquela que devia permanecer quieta, calada e não interromper a professora. Esta era autoritária colocava todos 
os alunos na linha e os castigos eram diversos, o pior era quando ela mandava ficarem todos de cabeça baixa durante muito tempo. Eu não precisava de castigo e sim de atenção, mais a situação piorou quando ela percebeu que eu escrevia com a mão esquerda, foi um tormento me obrigava escrever com a direita e dizia que eu era "contra Deus". Isso tudo tornou a escola um sofrimento não gostava de estar lá, mas tinha que suportar esta situação.

Neste período a educação era centrada no papel do professor que detinha o conhecimento, então não eram questionadas suas atitudes. O professor ditava as ordens, tratase de uma educação bancária ${ }^{3}$ a qual favorece a educação tecnocrata e conservadora fazendo com que os educandos aceitem a situação que os oprime sem questionar. Ao final da primeira série já sabia ler e escrever e também obedecer. Neste contexto permaneci até a quarta série.

Somente em 1983 que fui para quinta série na Escola Dr. Mario Chermont. Esta tinha fama de ter ensino de qualidade, professores aplicados, diretores preocupados com o bem estar dos alunos, uma merenda deliciosa. Dediquei-me muito aos estudos, minha amiga de infância Márcia também foi estudar nesta escola e foi maravilhoso, pois fazíamos parceria no período de provas estudávamos muito e as notas eram altas, os professores desconfiavam que houvesse "cola" nas nossas provas as notas eram as mesmas. Francisco, o professor de matemática dizia: "se eu não tivesse separado vocês diria que haviam colado”. Bem na verdade não havia "cola" era dedicação mesmo. E no fim do ano aprovação certa.

Um fator ímpar da escola era o Centro Cívico um local de discussão de alunos que defendiam os ideais estudantis. Lutavam pela carteira de meia passagem para estudante. Eu e minha amiga Márcia gostávamos de participar das passeatas em busca dessas conquistas. Foi uma luta árdua! Grandes passeatas, reuniões e debates sobre a importância da carteirinha de meia passagem para os estudantes, pois alguns tinham dificuldades financeiras para pagar passagem de ônibus. Hoje sinto orgulho de ter lutado por essa causa, pois essa carteira contribuiu para minha trajetória. E aproveito o momento para homenagear todos os heróis dessa luta.

Vale ressaltar, nesta escola tinha prazer em estudar, e me recordo com carinho dos professores que eu admirava-os e tinha um grande respeito por eles, pois sempre foram dedicados contribuíram com minha formação. Acredito que esta é a função social da escola contribuir para a formação de nossas crianças e adolescente para que possam tomar suas próprias decisões diante da sociedade.

\footnotetext{
${ }^{3}$ Freire, P. Pedagogia do Oprimido. 18. Ed. Rio de janeiro, Paz e Terra, 1987.
} 
Em 1988, comecei a fazer o segundo grau, queria continuar estudando de manhã, mais precisava trabalhar. Em minha família as mulheres começaram acessar o trabalho doméstico na adolescência e conseqüentemente pararam de estudar muito cedo. Eu também comecei a trabalhar de empregada doméstica aos 17 anos, o que desfavoreceu minha vida escolar foi difícil, comecei a trocar de colégio todo ano, fui estudar a noite no Colégio Pinto Marques, Augusto Meira e Deodoro de Mendonça.

Nesta época era comum o ensino técnico e cursei técnico em contabilidade. O ensino técnico preocupava-se em preparar o aluno para o mercado de trabalho, esta concepção ainda era resquício da educação tecnicista, em que professor é um técnico com eficiência e eficácia, e o aluno é um elemento para quem o material é preparado.

Entretanto, não me importava, pois minhas pretensões não eram ingressar em uma universidade e sim no mercado de trabalho, então estava no caminho certo. O colégio também não esclarecia a importância de cursar a universidade pública, entendia, portanto como o fim dos estudos o segundo grau. Afirmo que grande parte do meu desinteresse de acesso a universidade deu-se por falta de conhecimento que me foi negado e não havia uma política de incentivo ao aluno da escola pública para o acesso à universidade. Agora amparada por Frigotto (1999, p 179) entendo por que este direito me foi negado:

"A desqualificação da escola, por diferentes mecanismos aqui apenas referidos, constitui-se, ao lado dos mecanismos inseridos no próprio processo produtivo, numa forma sutil e eficaz de negar o acesso nos níveis mais elevados de saber à classe trabalhadora. Esta negação, por sua vez, constitui-se numa forma e mantê-la marginalizada das decisões que banalizam o destino da sociedade."

Diante disso, mais próximo que cheguei da universidade foi quando a Margateh minha patroa que trabalhava na Universidade Federal do Pará me mandava ir ao banco do Brasil posto da UFPA. Eu aproveitava para admirar a paisagem, me apaixonei é simplesmente lindo, o rio, as árvores, aquelas pessoas com muitos livros na mão, sempre sorrindo tão bonitas! Com seus belos carros. Contudo nunca me imaginei estudando lá, eu também acreditava que aquele lugar não era para pobre. Meu mundo não fazia parte dela. Além do mais na rua onde morava nunca tinha visto ninguém passar no vestibular. No meu imaginário aquele muro da universidade era muito grande e não podia alcançá-lo.

Mesmo trabalhando consegui concluir os meus estudos, afinal esta pessoa para quem trabalhava me incentivava a não desistir e comentava para eu fazer vestibular, e, eu tentei me escrevi no curso de contabilidade e como era de se esperar não passei. Devo fazer uma

Revista PET Interdisciplinar e Programa Conexões /UFPA On-line. Ed. Especial - 2017, BELÉM/ PA - ISSN 2447-097X 
ressalva, enfrentar o vestibular com o aprendizado adquirido na escola pública foi frustrante, pois o conteúdo do vestibular era muito específico e não fazia parte do currículo de técnico em contabilidade no qual conclui o segundo grau, sendo prejudicial para acesso à universidade de estudante que concluíam na escola pública.

Percebi então que seria necessário fazer um cursinho preparatório para o vestibular. Mais uma frustração o preço era mais alto que o meu salário. Como a universidade poderia fazer parte de minha classe social? Era humanamente impossível um pobre furar esta barreira de uma universidade elitizada. E como o sistema já me impulsionava a desistir, continuei a buscar novos caminhos que não fosse à universidade.

As minhas irmãs a mais velha (Linda) se casou e foi morar no Espírito Santo, conversei com meus pais e resolvi mudar para lá. Eu não queria ficar mais em Belém sentia a necessidade de novos vôos não podia passar minha vida trabalhando em casa de família, queria novas possibilidades, sempre sonhei conhecer outras cidades. Chegou o dia da viagem, a dona Margareth foi me deixar na rodoviária, estavam todos da família, foi uma choradeira, mas parti em direção ao desconhecido.

\section{Estado Santo: mudanças necessárias para o amadurecimento.}

Depois de três dias de viagem de ônibus, cheguei em outra cidade um lugar lindo, muitas praias, muitas pessoas adoráveis. A minha irmã trabalhava de garçonete no Hotel Escola SENAC, e logo informou que haveria uma prova para seleção de aluno para o curso de Recepcionista de Hotel e Empresa. Passei na prova e comecei o fazer o curso com uma bolsa para ajudar nos custos, ao final tirei a melhor nota do curso e fui encaminhado para trabalhar no Hotel Fazenda Flamboyant em outra cidade: Guarapari.

Devido conseguir o emprego fui morar em Vila Velha mais perto do trabalho na casa de uma amiga da família, Lucinha pessoa maravilhosa, com que morei durante dois anos até conseguir meu próprio espaço, com o dinheiro que recebia no Hotel deu para alugar um apartamento e dividir o aluguel com outra amiga (Cristina com quem eu passei dias maravilhosos). Nesta época também comecei a beber e fumar, namorar, gostava de curtir um pagode nas praias, sempre ficava em noitadas tinha muito amigos. Quando eu ficava só questionava minha vida, o que eu procurava? Qual o meu papel na sociedade? Qual o sentido de estar tão longe de meus pais? Tantas dúvidas que eu não conseguia responder.

Revista PET Interdisciplinar e Programa Conexões /UFPA On-line. Ed. Especial - 2017, BELÉM/ PA - ISSN 2447-097X 
Para superar estas crises trabalhava muito, sempre procurei cumprir com os meus compromissos, adorava meu trabalho, ficava fazendo horas extras, viajava a passeio para outras cidades, mandava uma ajuda todo mês para minha mãe. Após cinco anos na cidade de Vila Velha estava decidida a passar o resto de minha vida por lá tinha um bom emprego, bons amigos, estava bem profissionalmente.

Devo afirmar que vivenciei coisa boa, mas sofri muito também (...), conheci pessoas de toda estirpe, umas me odiaram e outras me amaram, ser mulher solteira e independente causa impacto na sociedade preconceituosa. Conheci a falsidade e a amizade e aprendi com as duas a ser mais solidária esperta e humilde diante de certas situações. Superei... Aprendi... Sobrevivi...! Considerando que sou um ser inacabado me aproprio de todo o conhecimento que me é proposto, atribuindo significado e importância para minha relação com eu e o mundo tento ser cada dia uma pessoa melhor e esta vivência me proporcionou amadurecimento.

Um golpe do destino no dia 14 de julho de 1996. Um telefonema! Começa a hora mais triste de minha vida! Meu pai 53 anos sofreu um ataque cardíaco, e estava morto! Essa notícia dá novos rumos a minha vida. Retorno à cidade de Belém, a cidade estava embassada meus olhos estavam tristes e cheios de lágrimas, pois tanto tempo sem ver meu pai, ira enterrá-lo. Uma sensação de perda e arrependimento de não estar ao seu lado na hora que ele mais precisava de mim, depois do enterro fiquei 20 dias em Belém.

De volta a Vila Velha não estava mais disposta a ficar, percebi que minha mãe precisava de mim ao seu lado. Estava decidida a voltar. Pedi demissão do hotel, deixei bons amigos e voltei pra casa. Decidi ficar ao lado da pessoa mais importante de minha vida, minha mãe. Hoje ela está com 79 anos é uma fofa!

(...) Descobre que as pessoas com que você mais se importa na vida são tomadas de você muito depressa, por isso sempre devemos deixar as vejamos.

as pessoas que amamos com palavras de amorosa, pode ser a ultima vez que

\section{Estou de volta pro meu aconchego...}

Chego a Belém em agosto 1998, na casa de minha mãe me receberam com carinho, a caçula esta de volta, minhas irmãs ainda trabalhavam em casa de família, meus irmãos pouco se importavam conosco. Comecei uma nova jornada em busca de emprego consegui em uma farmácia.

Revista PET Interdisciplinar e Programa Conexões /UFPA On-line. Ed. Especial - 2017, BELÉM/ PA - ISSN 2447-097X 
Entretanto o fato mais marcante de minha chegada na cidade foi a construção de minha família, conheci o Michel na rua de casa jogando bola (pra variar), me apaixonei, como eu sempre fui decidida marquei um encontro e começamos a namorar. Dois anos depois eu estava grávida por opção queria ser mãe, porém não foi à hora este sonho foi interrompida por um aborto espontâneo, outra perda que tive que superar... Sofrimento...

Procurei ajuda médica e de Deus para engravidar de novo. Assim depois de um ano tentando consegui engravidar. Gravidez de alto risco passava grande parte internada, parei de trabalhar, orava muito para que Deus me permitisse esse direito de ser mãe e fiquei com meu filho durante nove meses de luta até chegar o dia do parto.

Fui internada na Santa Casa de Misericórdia em Belém. Sofri muito fiquei dois dias esperando para o bebê nascer e nada, fui para a sala de parto as 14h00min do dias 20/07/1999 período de férias em hospital público é difícil.

As horas se passavam não havia médico só enfermeira e queriam que eu tivesse parto normal e fiquei sozinha naquela sala, já era 22h00min e ninguém fazia nada por mim, foi quando entreguei minha vida e de meu filho a Deus e disse que não aceitava que morrêssemos, pois já tínhamos lutado tanto para chegar aquele momento.

É leitor tu acreditas em milagre? Eu sim! Então entrou na sala um médico, perguntando desde que horas esta moça está aqui? A enfermeira o informou então ele depressa mandou que ela me preparasse para a cesariana. Eu senti como se tivesse nascido de novo, uma luz no fim do túnel. Nasceu o Mateus estava com sua pele roxa, pois já estava passado da hora de nascer. Mas vencemos essa luta juntos. Este foi mais um sonho que eu desejei e alcancei, hoje sou muito feliz com meu filho.

\section{A oportunidade para acesso a universidade chegou: Projeto COMUNI}

\section{"Comunidade na universidade"}

"Para que o mundo possa ser explicado criticamente, cumpre que a explicação mesma se coloque no terreno da práxis revolucionária... a realidade pode ser mudada de modo revolucionário só porque e só na medida em que nós mesmos produzimos a realidade, e na medida em que saibamos que a realidade é produzida por nós..." (KOSIK, 1995 p.22-23).

Ano de 2002 eu completava meus 31 anos, levava uma vida simples, trabalhando agora em uma padaria, acordava cinco horas da manhã para estar lá cedo e ganhava um 
salário mínimo, eu queria uma mudança urgente em minha vida profissional, resolvi fazer concurso para Prefeitura de Belém e me matriculei no Centro Comunitário 14 de abril que oferecia um curso preparatório com preço acessível à comunidade.

Lá fiquei sabendo sobre o projeto desenvolvido no local para estudantes de origem popular que gostariam de acessar a universidade. Em resumo o Projeto originou-se de um grupo de professores formados pela Universidade Federal do Pará em Ciências Sociais que ao realizarem uma pesquisa com jovens no bairro do Guamá, periferia de Belém que haviam terminado o nível médio, constatou que esses estudantes gostariam de cursar uma universidade e não tinham condições financeiras para pagar um cursinho pré-vestibular.

Então, com esses dados resolveram criar o cursinho pré-vestibular denominado COMUNI “Comunidade na Universidade” no Centro Comunitário.

Diante disso, percebi um pouco de mim nesta historia, pois este foi um dos motivos que há dez anos não possibilitou que eu passasse no vestibular, mas deixei de lado, naquele momento só me importava o concurso. No dia da prova a pontuação não foi tão boa, não para ficar com a vaga.

Devido minha pontuação no concurso, fiquei animada e fui convidar minha amiga Márcia que também tentou vestibular e não passou para estudarmos no Projeto. No começo minha família (mãe e irmãos) achava uma loucura, meu irmão falava que eu não tinha mais idade para estudar, mais eu não dava confiança para ele.

Já meu marido gostou da idéia, sempre confiou em meu potencial e contribuiu ficando com o Mateus (filho) agora com 03 anos, minha sogra também ajudava para que eu pudesse estudar.

A matrícula do cursinho custava $\mathrm{R} \$ 30,00$ por mês eu podia pagar era a chance para eu entrar na universidade mesmo depois de dez anos sem estudar acreditei. As aulas já haviam começado há cerca de quatro meses, mais ficamos assim mesmo, isso fez com que eu começasse a me interessar mais tinha que correr contra o tempo o vestibular era em dezembro e o programa era imenso. Eu tinha em mente que o sonho só é possível quando se luta para alcançá-lo.

O cursinho era muito cansativo terminava tarde e eu trabalhava na padaria, tinha dia que eu dormia na sala, não entendia quase nada, pois estava muito tempo afastada da sala de aula. Agora a matemática era contextualizada, minha primeira redação a professora me deu nota 0,5. Que incentivo! Próprio para alguém desistir, mas eu não desistia, pois eu queria provar para mim mesmo que seria capaz.

Revista PET Interdisciplinar e Programa Conexões /UFPA On-line. Ed. Especial - 2017, BELÉM/ PA - ISSN 2447-097X 
Chegou o dia da prova eram duas fases, e como era de se esperar não passei nem na primeira fase. Vi alguns colegas comemorando outros chorando. Eu não chorei, pois sabia que tudo dependia de meu esforço e naquele momento não foi o bastante para minha aprovação.

Resolvi tentar mais um ano e pedi demissão do emprego, eu tinha que passar neste vestibular e nada me impediria nem os obstáculos me esperavam neste ano de 2003. A turma ficou grande devido às aprovações muita pessoas se interessaram e eram 60 alunos na sala. Mudamos para a parte de cima do centro comunitário e a infra-estrutura era precária quando chovia as goteiras eram muitas, de vez em quando os ratos apareciam e comentávamos que eles já estavam ficando intelectuais de tanto assistirem aulas conosco. Além disso, tinha uns tiroteios na área e tínhamos que ficar escondidos, uma vez que a localização do Centro Comunitário é no bairro do Guamá um dos mais populosos de Belém, no qual o índice de criminalidade é alto e faz fronteira com o Bairro da Cremação que torna esta área denominada pela policia de linha vermelha, ou seja, de grande periculosidade.

Contudo no cursinho tínhamos os melhores professores a coordenação se empenhava bastante, eram voluntários que aceitaram o grande desafio de fazer com que pessoas sem uma perspectiva de acesso a universidade acreditasse na sua capacidade e seu direito a educação superior.

Diante desse incentivo, eu estava disposta a enfrentar este desafio, o primeiro obstáculo foi que o Michel ficou desempregado no mês de março, agora R \$ 30,00 fazia falta então parei de estudar não podia pagar. Foi quando a Dilma coordenadora do projeto me chamou e explicou a proposta do projeto que se o aluno não pudesse pagar ele podia assistir às aulas, então voltei. E minha cunhada Michele também foi estudar lá, ela me ajudava com as atividades, já que eu tinha muitas dificuldades, ela havia terminado o ensino médio naquele ano, sabia muito e me ajudava.

Surgiu uma proposta de trabalho. A tia do Michel me convidou para trabalha com ela no Pet Shop e eu aceitei precisava trabalhar. Passei a trabalhar o dia todo, a noite ia pro cursinho e depois continuava estudando em casa com a Michele até de madrugada.

Confesso a vocês que não foi fácil, em minhas orações sempre pedia a Deus força, saúde e sabedoria para alcançar o meu objetivo. Tinha dias que era difícil acordar. No Pet shop estava extremamente casada. Fiz desse ano um ano de mudança em minha vida, superei o cansaço, as dificuldades no aprendizado, parti para luta.

O processo do vestibular de 2004 foi modificado, passou a ter três fases PSS(processo seletivo seriado) 1, 2 e 3 ano e eu sentia que era minha vez de passar. Quando saiu a demanda 
meu curso por incrível que pareça estava 10 para uma vaga, fiquei preocupada. Pois pensava nos alunos de cursinho grande, que estavam estudando com todos os recursos possíveis, na flor da idade, mentes novas, colégios particulares, quem eram esses nove que estavam disputando esta vaga? Pensava muito nisso.

Contudo o diferencial do COMUNI, sempre foram os professores eles eram os nossos amigos, pois já haviam enfrentado essas dificuldades e sempre tinham uma palavra amiga para nós fortalecer, todos conseguiram acessar a universidade com muito esforço e sua experiência era nosso referencial.

No segundo semestre os colegas resolveram montar um grupo de estudo pela manhã e eu não podia participar, fiquei um pouco triste, mas tinha que trabalhar, então o Helio (colega de turma) perguntou se eu tinha condições de ficar até mais tarde no cursinho e respondi que sim. Outro grupo de estudo se formou de $22 \mathrm{~h}$ as $01 \mathrm{~h} 00$ da manhã. Sentia que era necessária dedicação total. No grupo de estudo tinham alguns colegas que tinha mais conhecimentos: o Murilo em Historia, a Michele em Biologia, o Dada em Português, o Helio em Matemática e o Wilson em Física e contribuíam com aqueles que tinham dificuldades. Solidariedade!!!

A permanência até muito tarde da noite no cursinho gerou muitos conflitos em famílias, era esposa com ciúmes dos maridos, namoradas aborrecidas e maridos bravos, pois não entendiam essas aulas até tarde. Quanto ao Michel tenho que agradecer que sempre me ajudou chegou até ir me buscar no cursinho tarde da noite. Ele era muito elogiado pelos meus professores por compreender e colaborar com minha decisão.

Enfim começa a maratona de provas: sábado as vésperas da primeira fase nós fizemos revisão com a professora Monica ela fez o desenho de uma escada no quadro e disse "este é o primeiro degrau, vão lá e subam "e aquelas palavras deu mais coragem, fiquei confiante. À noite eu não consegui dormir bem acordava assustada, pois sonhava que tinha perdido a hora, foi uma agonia, ficava pensando qual a questão que viria, uma ansiedade. De manhã cedo tomei um bom café e fui fazer a prova. Muito boa, ao conferir o gabarito o primeiro degrau tinha sido alcançado.

Continuamos estudando a prova seria em janeiro e passamos natal e ano novo no cursinho. O Professor Jonh, de História, "dizia natal e ano novo tem todo ano vamos estudar o ano que vem comemoramos" eu não pensava em nada só no vestibular, não queria perder tempo e a concorrência era grande eu principalmente que corria contra o tempo eu tinha que superar as dificuldades, já não agüentava mais tantas noites sem dormir.

Revista PET Interdisciplinar e Programa Conexões /UFPA On-line. Ed. Especial - 2017, BELÉM/ PA - ISSN 2447-097X 
Partimos para a segunda fase a prova foi muito difícil, tanto que ao chegar a minha casa não quis nem conferir o gabarito, pois estava chorando de medo, pensei que seria eliminada nesta fase então minha cunhada Michele conferiu o gabarito e disse que eu tinha passado para a terceira fase. Bem fiquei tranqüila, pois eu queria chegar à terceira fase, pois a prova era discursiva e eu tinha domínio na escrita e havia estudado muito para fazer uma boa redação e conseguiria passar.

Agora eu estava no segundo degrau e nada me impediria de chegar ao último, então pedi dispensa do trabalho a tarde para estudar mais. Enquanto isso meu marido e meu filho pouco me viam, a mamãe então reclamava que eu só ficava no cursinho. É verdade, abri mão de todos até o dia da prova.

Terceira fase meu irmão foi me levar e resolveu dar uma carona para um colega que faria prova na UFPA e eu faria no CEFET sentido contrário a avenida perimetral que leva até o CEFET estava engarrafada. Fiquei muito nervosa o tempo estava passado, estávamos no engarrafamento, mas o meu irmão pegou um atalho e cheguei ao local de prova faltando uns minutinhos para fechar o portão. Fiquei abalada, mas consegui fazer minha prova não podia perder para o nervosismo.

Depois da última prova o cursinho promoveu uma confraternização neste dia cantamos o nosso hino (Belém, Pará, Brasil do Mosaico de Ravena) e dançamos até de manhã, foi muito bom era como se estivéssemos aliviados, apenas a espera da aprovação.

$\mathrm{Na}$ véspera do resultado do vestibular não consegui dormi a noite queria que chegasse logo o horário da divulgação do listão no rádio (tradição paraense). Era um domingo e a dona do Pet shop pediu que eu fosse trabalhar e eu não quis ia sair o resultado do vestibular e no meu íntimo tinha certeza que estava aprovada. Estava muito nervosa nem consegui tomar café. Começou a sair o resultado eu já estava chorando, era como se algo dentro de mim dissesse que meu nome estava lá, não tinha dúvida disso investi tudo que o meu sonho se realizasse.

Domingo dia 22 de fevereiro no curso de Licenciatura Plena em Pedagogia da Universidade Federal do Pará. Depois de dez anos esperando por uma oportunidade MARIA ERMINEIDE DE PAULA LIMA, com 33 anos, filha de Nazaré e José, mãe de Mateus Lima e esposa de Michel Pereira, moradora do bairro da Cremação periferia de Belém é a primeira filha a alcançar uma vaga no Ensino Superior Público.

Alo!Alo! Papai. Alo! Mamãe. Ponha a vitrola pra tocar, pode soltar foguete que eu passei no vestibular. (Pinduca 1989).

Revista PET Interdisciplinar e Programa Conexões /UFPA On-line. Ed. Especial - 2017, BELÉM/ PA - ISSN 2447-097X 
Em síntese afirmo que nunca estive só nesta trajetória, além de minha família muitos amigos que não citei também contribuíram com esta conquista. Agora não consigo conter as lágrimas que rolam em meu rosto só de lembrar o quanto eu caminhei e como sou persistente, e sei que mereci o que conquistei, pois onde passei plantei humildade, sinceridade e amor. Agora estou colhendo os frutos dessa plantação. No qual consegui contrariar a lógica de uma estrutura desigual que impede o acesso de estudantes de origem popular a universidade pública, mesmo sendo este direito de todos, poucos usufrui dele.

Referências:

FRIGGOTO, G. A produtividade da escola improdutiva. São Paulo: Cortez, 1999

KOSIK, K. Dialética do Concreto. São Paulo: Paz e Terra, 1995.

SOARES, Magda. Metamémoria-memórias: travessia de uma educadora. São Paulo: Cortez, 2001 